\title{
ALGUNAS CUESTIONES QUE PLANTEA LA MODIFICACIÓN, EN ESPAÑA, DE LAS MEDIDAS DE GUARDA Y CUSTODIA ADOPTADAS POR TRIBUNALES EXTRANJEROS A LA LUZ DEL AUTO DE LA AUDIENCIA PROVINCIAL DE BARCELONA DE 29 DE ENERO DE 2020
}

\author{
SOME ISSUES RAISED BY THE MODIFICATION, IN SPAIN, OF \\ THE GUARDIANSHIP AND CUSTODY MEASURES ADOPTED \\ BY FOREIGN COURTS IN THE LIGHT OF THE ORDER OF THE \\ PROVINCIAL HEARING OF BARCELONA OF JANUARY 29, 2020
}

\author{
Mercedes SABIDo Rodríguez \\ Profesora Titular de Derecho internacional privado. \\ Universidad de Extremadura. \\ ORCID ID: 0000-0003-1627-6725
}

Recibido: 12.11.2020 / Aceptado: 04.12.2020

DOI: https://doi.org/10.20318/cdt.2021.6017

\begin{abstract}
Resumen: El planteamiento de una demanda de modificación de las medidas de guarda y custodia adoptadas por un tribunal extranjero suscita algunas dificultades. En este trabajo analizaremos las que ha puesto de relieve el Auto de la Audiencia Provincial de Barcelona de 29 de enero de 2020 por el que se resuelve el recurso de apelación contra la resolución de instancia que inadmitió a trámite la demanda de modificación de medidas adoptadas por un tribunal marroquí. Abordaremos la determinación de la competencia judicial internacional de los tribunales españoles, diferenciándola de la competencia territorial; así como la problemática relativa a la exigencia o no del previo reconocimiento de la decisión cuya modificación se pretende y, en su caso, el procedimiento a seguir.

Palabras clave: modificación de medidas, guarda y custodia de menores, competencia judicial internacional, competencia territorial de los tribunales españoles, reconocimiento y ejecución de decisiones extranjeras.

Abstract: The presentation of a demand for modification of the custody and custody measures adopted by a foreign court raises some difficulties. In this work we will analyse those that have been highlighted by the Order of the Provincial Court of Barcelona of January 29, 2020, which resolves the appeal against the decision of instance that inadmissible the request for modification of measures adopted by a Moroccan court. We will address the determination of the international judicial competence of the Spanish courts, differentiating it from functional competence; as well as the problems related to the requirement or not of prior recognition of the decision whose modification is intended and, where appropriate, the procedure to follow.
\end{abstract}

Keywords: modification of measures, custody of minors, international jurisdiction, territorial jurisdiction of spanish courts, recognition and enforcement of foreign decisions. 
Sumario: I. Introducción: antecedentes y origen del Auto de la Audiencia Provincial de Barcelona de 29 de enero de 2020. II. La competencia de los tribunales españoles en litigios relativos a la modificación de medidas adoptadas por una decisión extranjera. 1. La competencia judicial internacional y la competencia territorial, objetiva y funcional. 2. La ordenación de la competencia judicial internacional para modificar medidas de guarda y custodia de menores. 3. La concreción del órgano competente. III. El reconocimiento y ejecución de la decisión extranjera. 1. Sobre la necesidad o no de reconocimiento de la decisión extranjera objeto de modificación. 2. Precisión del sistema de reconocimiento aplicable.

\section{Introducción: Antecedentes y origen del Auto de la Audiencia Provincial Barcelona de 29 de enero de 2020}

1. Nuevamente se plantean, ante la Audiencia Provincial de Barcelona, dos cuestiones que tradicionalmente suscita el planteamiento en España de procesos relativos a la modificación de medidas adoptadas por autoridades extranjeras. Una primera, relativa a la determinación de la competencia judicial internacional de los tribunales españoles; y la segunda, relacionada con la exigencia o no del previo reconocimiento de la decisión cuya modificación se pretende. Ambas cuestiones son abordadas, en mayor o menor medida, en el Auto de la Audiencia Provincial de Barcelona de fecha 29 de enero de $2020^{1}$, objeto del presente estudio. En estas cuestiones centraremos, por tanto, nuestra atención partiendo, para ello, de las circunstancias que rodean el supuesto y que configuran el marco en el que se adopta la decisión del tribunal español.

2. Los hechos que dan lugar al pronunciamiento de la Audiencia tienen su origen en la demanda de modificación de medidas de divorcio contencioso interpuesta por D. Luis Francisco ante el JPI de Barcelona en cuya virtud interesa la modificación de la sentencia dictada, con fecha 12 de julio de 2012, por el Juzgado de Primera Instancia de Ksar El Kebir (Marruecos) parcialmente revocada por la Sentencia $n^{\circ} 943$ de 10 de diciembre de 2018, dictada por el Tribunal de apelación de Tánger. Mediante Auto de 21 de mayo de 2019, el juzgado inadmite a trámite la demanda considerando que, con base en el artículo 775 LEC, la competencia para acordar la modificación de las medidas adoptadas por la sentencia extranjera corresponde al órgano judicial que la dictó. Disconforme con la decisión adoptada por el tribunal de instancia, D. Luis Francisco interpone recurso de apelación, fallando la Audiencia Provincial de Barcelona la revocación del auto impugnado.

3. En su decisión, la Audiencia fundamenta la revocación del auto recurrido con base en los siguientes argumentos: En primer lugar, afirma la aplicabilidad de los artículos 775.1 y 61 LEC a los litigios relativos a situaciones vinculadas únicamente con territorio nacional y señalando que, con base en el artículo 45 LCJIMC, la posibilidad de modificar una decisión extranjera por los tribunales españoles está condicionada por la obtención previa de su reconocimiento. En segundo lugar, la Audiencia afirma que la competencia judicial internacional de los tribunales españoles en el presente caso, atendiendo a la nacionalidad marroquí de los litigantes, se articula a partir de lo dispuesto en el artículo 21.1 LOPJ. En su virtud, considera en tercer lugar, la aplicabilidad del Convenio celebrado entre España y Marruecos, con fecha 30 de mayo de 1997, de cooperación judicial en materia civil, mercantil y administrativa y, en su defecto, de la norma recogida en el artículo 22 quater c) LOPJ en orden a determinar la competencia judicial internacional de los tribunales españoles.

4. A partir de estas consideraciones, con base en lo dispuesto en el artículo 22 quater c) LOPJ, la Sala afirma la competencia judicial internacional de los tribunales españoles en tanto que tribunal del Estado de la residencia habitual del actor un año antes de la interposición de la demanda. Asimismo, el tribunal fundamenta su decisión en la concurrencia de la residencia habitual del menor en España ex artículo

${ }^{1}$ Auto de 29 de enero de 2020 dictado por la Sección 12a de la Audiencia Provincial de Barcelona (ECLI: ES:APB:2020:614A) 
8.1 del Reglamento 2201/03 relativo a la competencia, el reconocimiento y la ejecución de las resoluciones judiciales en materia matrimonial y de responsabilidad parental (en adelante, Reglamento 2201/03) 2 .

5. Aunque, acertadamente, el tribunal aborda la necesidad de determinar la competencia judicial internacional de los tribunales españoles para conocer del proceso de modificación de las medidas adoptadas una decisión extranjera, confirmándola, los argumentos en los que fundamenta su decisión deben ser analizados, entre otras razones, porque no delimita las normas aplicables y la relación entre cada una de ellas y aborda, conjunta y confusamente, junto a la competencia judicial internacional de los órganos españoles aspectos relacionados con la eficacia extraterritorial de la decisión extranjera cuya modificación se pretende.

\section{La competencia de los tribunales españoles en litigios relativos a modificación de medidas adoptadas por una decisión extranjera}

\section{La competencia judicial internacional y la competencia territorial, objetiva y funcional}

6. La modificación de medidas adoptadas en el marco de un proceso de divorcio, es una pretensión comúnmente planteada en el marco de litigios vinculados a divorcios. Las obligaciones y relaciones derivadas del matrimonio no se disuelven como consecuencia de la disolución del vínculo matrimonial sino que continúan existiendo. Su ordenación se lleva a cabo en la decisión que declara la disolución del vínculo en la que, atendiendo a las circunstancias que concurren en el momento, se establece la atribución de la patria potestad de menores, el ejercicio de la guarda y custodia y el establecimiento de un determinado régimen de visitas, el uso de la vivienda familiar así como el establecimiento de la pensión alimenticia o, en su caso, de una pensión compensatoria.

7. En unos casos las medidas vinculadas a la declaración de divorcio, separación o nulidad se extinguen bien de forma automática, como ocurre con las relacionadas con los menores al alcanzar la mayoría de edad, bien por el transcurso del tiempo establecido para ella, como en el supuesto de pensión compensatoria. En otros supuestos, en cambio, cuando las circunstancias a partir de las cuales aquellas medidas fueron adoptadas cambian sustancialmente es necesario plantear la correspondiente demanda para adecuar su régimen. Una demanda de modificación de medidas que implica la iniciación de un proceso nuevo, autónomo e independiente de aquel en el que las mismas fueron adoptadas inicialmente.

8. El planteamiento de este nuevo proceso destinado a modificar las medidas para adecuarlas a las nuevas circunstancias que concurran requiere la determinación, en primer lugar, del órgano competente para conocer. Para ello, las normas de competencia interna previstas, con carácter general en la LEC, atendiendo a criterios territoriales, objetivos y funcionales, determinan cuál de los tribunales españoles conocerá del supuesto. No obstante, en otros casos, cuando el supuesto presenta un elemento extranjero por estar vinculado a varios Estados, antes de resolver la competencia interna debemos concretar, mediante el recurso al sistema de Derecho internacional privado español, si corresponde a los tribunales españoles la competencia judicial internacional para conocer. Es lo que ocurre en el supuesto resuelto por la Sala. Entre otros elementos, el hecho de que el litigio verse sobre la modificación de medidas adoptadas por un tribunal extranjero, requiere determinar, con carácter previo a la competencia interna, si los tribunales españoles tienen competencia judicial internacional. Como declaró el Tribunal Constitucional en su STC 61/00, la inadmisión de una demanda de modificación de medidas no puede fundamentarse en la falta de jurisdicción por tratarse de una decisión extranjera; debe valorarse previamente la propia competencia de nuestro tribunal.

\footnotetext{
${ }^{2}$ Reglamento (CE) núm. 2201/03 del Consejo, de 27 de noviembre de 2003, relativo a la competencia, el reconocimiento y la ejecución de las resoluciones judiciales en materia matrimonial y de responsabilidad parental, por el que se deroga el Reglamento (CE) núm. 1347/00 (DO L 338, de 23 de diciembre de 2003)

${ }^{3}$ Sentencia del Tribunal Constitucional 61/00, de 13 de marzo de 2000 (BOE núm. 90 de 20 de abril).
} 
9. En el supuesto analizado, la decisión de instancia, como hemos señalado, inadmite a trámite la demanda por considerar que incumple los requisitos de admisibilidad. Esta solución, que no distingue la competencia judicial internacional de la competencia interna, se fundamenta en la aplicación de estas últimas para decidir la competencia judicial internacional de los tribunales españoles. En particular, el auto de instancia se basa en el artículo 775 LEC, en cuya virtud la demanda debe interponerse ante el tribunal que dictó la resolución cuya modificación se pretende. Acertadamente, el tribunal de apelación distingue ambos conceptos y, en consecuencia, revoca la decisión apelada.

10. La competencia judicial internacional se articula a partir de las normas que integran nuestro sistema de Derecho internacional. Aplicar una norma de competencia interna para su concreción supone una merma de la tutela judicial efectiva. En esta línea se ha manifestado el Tribunal Constitucional. En su sentencia 61/00, antes citada, afirma que tal solución supone una vulneración del derecho a la tutela judicial efectiva consagrado en el artículo 24 CE en la medida en que impide el conocimiento del asunto por cualquier tribunal español basándose para ello en una regla que únicamente reparte la competencia entre los tribunales españoles y cuyos principios y objetivos difieren de las disposiciones que ordenan la competencia judicial internacional de los órganos judiciales españoles. Las normas de competencia judicial internacional delimitan el ejercicio de la potestad jurisdiccional atendiendo a las exigencias derivadas del derecho a la tutela judicial efectiva proyectada en el principio de proximidad. Solo en ellas puede darse respuesta a la cuestión de si es posible que los tribunales españoles conozcan de una determinada pretensión, pues solo ellas responde a las exigencias necesarias para que nuestros tribunales puedan asumir la tutela judicial efectiva del caso concreto.

11. En los siguientes apartados tendremos ocasión de exponer, en el marco del supuesto analizado, las soluciones acogidas tanto en orden a determinar la competencia judicial internacional de los tribunales españoles para resolver la demanda planteada como las relativas a la concreción del órgano jurisdiccional español que resultaría territorial y funcionalmente competente.

\section{La ordenación de la competencia judicial internacional para modificar medidas de guarda y custodia de menores.}

12. En el sector de la competencia judicial internacional, el sistema español de Derecho internacional privado está integrado por un conjunto de normas de distinto origen. Junto a las normas de producción autónoma, elaboradas por el legislador español, coexisten disposiciones de origen institucional y convencional. Ciertamente, esta pluralidad normativa dificulta su aplicación ${ }^{4}$, máxime cuando esta pluralidad aumenta en función de la medida afectada. Es importante, en este punto, determinar los principios y criterios ordenadores de las relaciones entre las distintas fuentes. De este modo, junto a los principios de primacía, jerarquía y competencia, la delimitación del ámbito de aplicación de cada una de ellas y las cláusulas de compatibilidad previstas en los textos europeos y convencionales permiten concretar la disposición aplicable para decidir acerca de la competencia judicial internacional de nuestros tribunales en litigios como el planteado por la representación procesal de D. Luis Francisco.

13. La dificultad que plantea la aplicación del sistema de competencia judicial internacional se agrava en el marco de los litigios relativos a la modificación de medidas adoptadas en una sentencia de divorcio dictada por autoridades extranjeras porque dicho sistema varía en función de la medida cuya modificación se pretende. De un lado, las normas aplicables a los litigios que únicamente tiene por objeto la modificación de la medida relativa a guarda y custodia de menores, que es la que ocupa en el presente asunto al juzgado de instancia según la información recibida por parte de la defensa del actor, y

\footnotetext{
${ }^{4}$ Véase, F. Garau Sobrino, "Notas sobre la colisión de fuentes de Derecho internacional privado español sobre responsabilidad parental y protección del niño" Cuadernos de Derecho Transnacional, Vol. 3, No. 1, 2011, pp. .282-289
} 
a la que limitaremos nuestro análisis. De otro, las disposiciones aplicables para resolver la modificación de medidas relacionadas con la obligación de alimentos o la pensión compensatoria ${ }^{5}$.

14. La acción relativa a la modificación de la medida relativa a la guarda y custodia de menores no encuentra norma específica en ninguna disposición. No obstante, su inclusión en el ámbito de aplicación material del Reglamento 2201/03 se justifica, a tenor de lo dispuesto en el artículo 1 del texto europeo, porque se trata de medidas incardinadas en el marco de la "atribución, el ejercicio, la delegación, la restricción o la finalización de la responsabilidad parental". En particular, es una medida referida al derecho de custodia y al derecho de visita. En términos similares el supuesto es subsumible materialmente también en el ámbito de aplicación del Convenio de La Haya de 1996 relativo a la competencia, la ley aplicable, el reconocimiento, la ejecución y la cooperación en materia de responsabilidad parental y de medidas de protección de los niños ${ }^{6}$ (en adelante, Convenio de La Haya de 1996) que, conforme a sus artículos 1 y 3 , tiene por objeto determinar la autoridades competentes y la ley aplicable a las medidas relativas a la atribución, ejercicio y privación de la responsabilidad parental, el derecho de guarda así como el derecho de visita. Por último, dado que en el sector de la competencia judicial internacional no ha sido celebrado ningún convenio bilateral entre España y Marruecos, únicamente faltaría por incluir entre las fuentes relacionadas las normas recogidas en los artículos 22 ter y 22 quater d) de la LOPJ relativo, este último, a las relaciones paterno-filiales, protección de menores y de responsabilidad parental.

15 Señaladas las disposiciones a partir de las cuales se ordena la competencia judicial internacional de los tribunales españoles en el marco de la modificación de las medidas relativas a la guarda y custodia de menores, procede la concreción de la norma aplicable atendiendo a las circunstancias fácticas y jurídicas que concurren en el supuesto así como a los principios que rigen las relaciones entre las distintas fuentes normativas. En el fundamento jurídico primero del Auto que analizamos, la Audiencia se refiere al artículo 8.1 del Reglamento 2201/03 si bien parece determinar su aplicabilidad con carácter subsidiario al artículo 22 quater c) LOPJ y en el artículo 1 del Convenio bilateral entre España y Marruecos, de 30 de mayo de 1997, relativo a la Cooperación Judicial en Materia Civil, Mercantil y Administrativa ${ }^{7}$, fundamentando en las disposiciones contenidas en estos últimos preceptos el fallo revocatorio. La solución es correcta, pero el fundamento utilizado es erróneo.

16. En primer lugar, por lo que al texto europeo se refiere, en virtud del principio de primacía, el Reglamento 2201/03 desplaza la aplicación de las normas contenidas en la LOPJ para aquellos supuestos subsumibles en su ámbito de aplicación. Tratándose de una acción de responsabilidad parental, en los términos expuestos, relativa a un menor con residencia habitual en un Estado miembro, la competencia de los tribunales españoles se determina conforme a lo dispuesto en el Reglamento europeo. Dada las circunstancias del supuesto enjuiciado, las dificultades se podrían haber planteado en relación con la posible aplicabilidad del citado Convenio de La Haya de 1996, del que tanto España como Marruecos son Estados Parte. No obstante, tampoco sería este texto aplicable a tenor de lo dispuesto en el artículo 61 del Reglamento 2201/03. Mediante la cláusula de compatibilidad en él prevista ambos textos coexisten, siendo aplicable el Convenio en aquellos supuestos relativos a la responsabilidad parental y medidas de

\footnotetext{
${ }^{5}$ Entre otras, el Reglamento 4/2009, de 18 de diciembre de 2008, relativo a la competencia, la ley aplicable, el reconocimiento y ejecución de resoluciones y la cooperación en materia de obligaciones de alimentos ( $D O \mathrm{~L} 7$, de 10 de enero), Convenio sobre cobro internacional de alimentos para los niños y otros miembros de la familia, hecho en La Haya el 23 de noviembre de 2007 ( $D O$ L 192, de 22 de julio ) y las normas recogidas en los artículos 22 ter y 22 quater f) de la LOPJ en la medida en que ambos textos regulan las obligaciones de alimentos derivadas de una relación familiar, de parentesco, matrimonio o afinidad.

${ }^{6}$ Convenio relativo a la competencia, la ley aplicable, el reconocimiento, la ejecución y la cooperación en materia de responsabilidad parental y de medidas de protección de los niños, hecho en La Haya, el 19 de octubre de 1996 (BOE núm. 291, de 2 de diciembre de 2010)

${ }^{7}$ Convenio de Cooperación Judicial en Materia Civil, Mercantil y Administrativa entre el Reino de España y el Reino de Marruecos, hecho en Madrid el 30 de mayo de 1997 (BOE núm. 151, de 25 de junio de 1997)
} 
protección de menores cuando estos tengan su residencia habitual en un Estado parte que no sea miembro de la Unión Europea ${ }^{8}$.

17. En segundo lugar, en cuanto a la aplicación del convenio bilateral, si bien es cierto que en su artículo 1 consagra el derecho al acceso a la justicia de los nacionales de los Estados Parte para actuar en la defensa de sus derechos, a tenor de su artículo 22, el texto convencional no tiene por objeto la regulación de la competencia judicial internacional. Como hemos señalado, sin perjuicio de que más adelante, en el marco de la eficacia extraterritorial de decisiones, recurramos a este texto, el mismo no resulta aplicable para determinar la competencia judicial internacional de los tribunales españoles en el supuesto enjuiciado.

18. En su auto la Audiencia afirma que el menor reside habitualmente en Villanueva y Geltrú por lo que, de acuerdo con cuanto antecede, la determinación del tribunal internacionalmente competente debe efectuarse conforme al sistema de foros establecido en el Reglamento 2201/03.

19. El artículo 8 del texto europeo establece, con carácter general, la competencia judicial internacional de los tribunales del Estado miembro en el que reside habitualmente el menor. Junto a esta previsión, los artículos 9 a 12 configuran las excepciones o modulaciones a la regla general, algunas de las cuales pueden resultar aplicables en el marco de procedimientos relativos a la modificación de medida de responsabilidad parental. Nos estamos refiriendo, en particular, a la excepción recogida en su artículo $9^{9}$. En litigios relativos a la modificación de resoluciones relativas al derecho de visita dictadas por el Estado de residencia habitual del menor, cuando se produce un cambio de residencia habitual del menor, el precepto consagra el mantenimiento de la competencia de los tribunales del Estado miembro de la primera residencia habitual del menor durante tres meses y siempre que el titular del derecho resida en dicho Estado. Esta prolongación de la competencia puede ser excepcionada en aquellos supuestos en los que el titular del derecho de visita se someta a la competencia de los tribunales del lugar de la nueva residencia del menor. Aunque esta última exigencia pudiera concurrir en el supuesto de autos, el precepto no sería aplicable porque o bien no se ha producido cambio de Estado de residencia habitual (entendiendo que a tenor de la resolución el menor ha residido siempre en nuestro país desde su nacimiento en Huesca) o bien de haberse producido dicho cambio, pudiera ocurrir que la residencia habitual anterior se encontraba en un Estado no miembro (considerando que el menor hubiera tenido su residencia en Marruecos, Estado de origen de la decisión cuya modificación se pretende).

20. El artículo 22 quater c) LOPJ no constituye el fundamento de la competencia judicial de los tribunales españoles en el presente caso como, erróneamente, afirma la Audiencia. En este marco, la Sala atribuye competencia a los tribunales españoles con base en la residencia habitual del actor en España "desde un año antes de la interposición de la demanda". Un criterio que, de acuerdo con el tenor literal del precepto citado, tampoco sería correcto. El artículo 22 quater d) LOPJ, con independencia de las críticas que puedan realizarse al mismo ${ }^{10}$, establece varios de foros de competencia que actúan alternativamente y están referidos a la residencia habitual en España del hijo o menor al tiempo de interposición de la demanda; la nacionalidad española del actor; o su residencia habitual en España. En todo caso, requiere el precepto, la concurrencia de los foros al menos seis meses antes de la presentación de la demanda.

\footnotetext{
${ }^{8}$ Sobre las características actuales del Derecho de familia europeo y, en particular, la coexistencia y convivencia con la codificación internacional, vid. S. Álvarez GonZÁlez, "Una visión general posible del Derecho internacional privado de familia en la UE", Diario La Ley, La Ley 1718/2018.

${ }^{9}$ El precepto del texto europeo difiere, en este punto, de la previsión contenida en el artículo 14 del Convenio de La Haya 96. De acuerdo con este último, las medidas adoptadas con base en los criterios de competencia establecidos en el texto convencional, aunque se produzca un cambio de las circunstancias en las que aquella competencia se fundamentan, hasta que las autoridades competentes no las hayan modificado. De otro lado, en el marco de la cooperación entre Estados Parte, el artículo 35 establece las posibilidades de actuación de sus autoridades cuando se promueva por un progenitor la modificación del derecho de visita concedido por las autoridades del Estado de la antigua residencia habitual (artículo 35).

${ }^{10}$ Vid. J.C. Fernández Rozas/S. SÁnchez Lorenzo, Derecho internacional privado, 2020, p. 407.
} 
21. Atendiendo a las circunstancias que rodean el supuesto litigioso, la competencia judicial para conocer de la demanda de modificación de medidas planteada por el actor corresponde a los tribunales españoles de acuerdo con lo dispuesto en el artículo 8 del Reglamento 2201/03 por encontrarse el menor residiendo habitualmente en España ${ }^{11}$.

\section{La concreción del órgano competente}

22. Correspondiendo a los tribunales españoles la competencia judicial internacional para conocer de la demanda interpuesta por la representación procesal de D. Luis Francisco con el objeto de modificar las medidas de guarda y custodia adoptadas por la decisión marroquí, la determinación del concreto tribunal debe realizarse conforme a las normas de competencia territorial, objetiva y funcional previstas en la LEC. En este punto, las discrepancias entre las normas de la LEC y las previstas en el sistema de competencia judicial internacional suscitan algunas dificultades.

23. Tras la reforma de $2015^{12}$, el artículo 775 de LEC dispone que la competencia para conocer del proceso de modificación de medidas corresponde al mismo tribunal que las acordó. El legislador no solo parece obviar la independencia del proceso de modificación de medidas respecto del proceso en el que las mismas fueron adoptadas inicialmente, sino que, además, no tiene en cuenta el lugar de residencia del menor como criterio de distribución de la competencia del tribunal español. En relación con este último aspecto, el Tribunal Supremo viene reiterando que, frente a la virtualidad indudable del fuero de proximidad, la competencia del órgano jurisdiccional que adoptó las medidas aporta como ventajas un factor de calidad en la decisión, ya que es el juzgado que se encuentra en mejor posición para valorar el cambio de circunstancias, y la seguridad jurídica inherente a un fuero unívoco y exclusivo que evita conflictos de competencia. Y, en cuanto a los posibles inconvenientes que pudiera generar, entiende que pueden minimizarse mediante el recurso a distintas vías de cooperación, auxilio y desplazamiento judicial previstas en la ley ${ }^{13}$.

24. La doctrina ha puesto de relieve la disparidad de criterios en las normas reguladoras de la competencia judicial internacional y aquellas que ordenan la competencia territorial de los tribunales españoles ${ }^{14}$. Una disparidad que demuestra una diferente concepción del interés del menor, se aleja de la idea de armonización de las diferentes legislaciones y cuestiona la configuración del procedimiento de modificación de medidas como independiente y autónomo. La imposibilidad de aplicar la disposición recogida en el artículo 775 LEC para supuestos internacionales como el que nos ocupa ha sido solventada mediante el recurso a la norma recogida en el artículo $769.3 \mathrm{del}$ mismo texto legal ${ }^{15}$. Esta última disposición establece foros alternativos que permiten al demandante elegir el tribunal español competente

\footnotetext{
${ }^{11}$ Véase la STJUE de 15 de febrero de 2017, as. C-499/2015, W, Vy X (ECLI:CU:C:2017:118)

${ }^{12}$ Redactado conforme al apartado setenta y dos del artículo único de la Ley 42/2015, de 5 de octubre, de reforma de la LEC (BOE de 6 de octubre) el artículo 775, relativo a la Modificación de las medidas definitivas, dispone: 1. El Ministerio Fiscal, habiendo hijos menores o incapacitados y, en todo caso, los cónyuges, podrán solicitar del tribunal que acordó las medidas definitivas, la modificación de las medidas convenidas por los cónyuges o de las adoptadas en defecto de acuerdo, siempre que hayan variado sustancialmente las circunstancias tenidas en cuenta al aprobarlas o acordarlas. 2. Estas peticiones se tramitarán conforme a lo dispuesto en el artículo 770. No obstante, si la petición se hiciera por ambos cónyuges de común acuerdo o por uno con el consentimiento del otro y acompañando propuesta de convenio regulador, regirá el procedimiento establecido en el artículo 777. 3. Las partes podrán solicitar, en la demanda o en la contestación, la modificación provisional de las medidas definitivas concedidas en un pleito anterior. Esta petición se sustanciará con arreglo a lo previsto en el artículo 773.

${ }^{13}$ Per omnia, Auto de 20 de octubre de 2020, (Roj: ATS 9289/2020 - ECLI: ES:TS:2020:9289A)

${ }^{14}$ B. UReÑa Carazo, "Competencia judicial internacional y modificación de medidas: pautas para su determinación”, $L a$ Ley Derecho de Familia, núm. 17, La Ley 1896/2018.

${ }^{15}$ Art. 769.3. LEC En los procesos que versen exclusivamente sobre guarda y custodia de hijos menores o sobre alimentos reclamados por un progenitor contra el otro en nombre de los hijos menores, será competente el Juzgado de Primera Instancia del lugar del último domicilio común de los progenitores. En el caso de residir los progenitores en distintos partidos judiciales, será tribunal competente, a elección del demandante, el del domicilio del demandado o el de la residencia del menor.
} 
para conocer de la demanda de modificación de medidas adoptadas por un tribunal extranjero. Estos criterios determinan la competencia del tribunal español correspondiente al domicilio del demandado o al del lugar de la residencia del menor. Es la solución adoptada por el Auto del Tribunal supremo de 17 de noviembre de 2019 en el marco de la modificación de medidas en materia de alimentos ${ }^{16}$.

25. De otra parte, los foros previstos en el Reglamento 2201/03 son foros con doble valencia. Esta configuración permite superar la falta de armonía entre las normas de competencia judicial internacional y las reguladoras de la competencia territorial de los tribunales españoles. El criterio previsto en el artículo 8 del texto europeo permitirá concretar el órgano español competente para conocer del litigio planteado. ${ }^{17}$

\section{EI reconocimiento de la decisión extranjera}

\section{Sobre la necesidad o no de reconocimiento de la decisión extranjera objeto de modificación.}

26. Tradicionalmente la necesidad o no de reconocer la decisión extranjera cuya modificación se pretende ante los tribunales españoles ha centrado el debate en la doctrina y ha justificado una amplia y diversa jurisprudencia, en ausencia de norma que lo determinara. Junto a resoluciones que modificaban medidas adoptadas por decisiones extranjeras de divorcio como si de una decisión española se tratase ${ }^{18}$, otras que condicionaban su pronunciamiento a la necesidad de requerir previamente el reconocimiento o execuátur de la decisión que se pretendía modificar ${ }^{19}$.

27. En primer término, delimitaremos las normas reguladoras del sector en materia de responsabilidad parental aplicables atendiendo a las circunstancias del litigio planteado ante el juzgado de instancia. Ello nos permitirá concluir la necesidad o no de reconocimiento de la decisión adoptada por las autoridades marroquíes. En este punto, dado que el Estado origen de la decisión no es un Estado miembro, las normas sobre eficacia extraterritorial de decisiones recogidas en el citado Reglamento 2201/03 no resultan aplicables. Corresponderá bien al Convenio de La Haya de 1996 bien o a los convenios bilaterales celebrados entre España y Marruecos ${ }^{20}$, determinar, en su caso, la necesidad o no de reconocer la decisión así como el procedimiento a seguir. En su defecto, debemos recurrir al sistema de producción autónoma recogido en los artículos 41 y siguientes de la LCJIMC.

28. Por lo que a la necesidad o no de reconocimiento de la decisión extranjera cuya modificación se promueve ni el Convenio de 1996 ni los Convenios bilaterales entre España y Marruecos se pronuncian sobre este aspecto limitándose a regular los mecanismos, requisitos y condiciones para reconocer y ejecutar en un Estado Parte las decisiones adoptadas en otro Estado también Parte. Acertadamente, la Sala en relación con este punto hace referencia al artículo 45 de la LCJIMC. No obstante, teniendo en cuenta el pronunciamiento del auto apelado y los términos en los que se habrá planteado el recurso, la Sala se limita a afirmar que "sin perjuicio de la necesidad de proceder al previo reconocimiento en España de la resolución a modificar conforme a los arts. 22 y ss. del indicado Convenio-inclusive a modo

${ }^{16}$ Auto del TS de 17 de septiembre de 2019 (ECLI:ES:TS:2019:9225A). Véase M.J. VALVERDE Martínez, “Competencia en la modificación por los tribunales españoles de medidas relativas a alimentos establecidas por tribunales extranjeros. Comentario al Auto del Tribunal Supremo de 17 de septiembre de 2019”, Cuadernos de Derecho Transnacional (Marzo 2020), Vol. 12, N 1, pp. 763-775

${ }^{17}$ En esta línea se ha pronunciado la sección $12^{\text {a }}$ de la Audiencia Provincial de Barcelona, en su auto de fecha 25 de mayo de 2019 (ECLI: ES:APB:2019:3108A)

${ }^{18}$ SAP de La Rioja (Sección 1ª) núm. 270/2004 de 7 octubre (JUR/2004/286103); SAP de Barcelona (Sección $18^{\mathrm{a}}$ ) núm. 3/2006 de 4 enero (AC\2006\183.)

${ }^{19}$ SAP de Sevilla (Sección 2a).Auto núm. 120/2010 de 27 mayo (JUR\2010\371422).

${ }^{20}$ Junto al anteriormente citado, también encontramos el Convenio entre el Reino de España y el Reino de Marruecos relativo a la asistencia judicial y reconocimiento y ejecución de decisiones relativas a derecho de custodia, derecho de visita y devolución de menores, hecho en Madrid el 30 de mayo de 1997 (BOE núm. 150, de 24 de junio) 
incidental en el presente litigio tal como prevén el apartado VIII del Preámbulo y los arts. 44.2 y 45.1 de la Ley 29/15, de 30 de julio, de cooperación jurídica internacional en materia civil".

29. Efectivamente, la LCJIMC, entre sus novedades, prevé que las resoluciones extranjeras firmes o definitivas susceptibles de ser modificadas, como ocurre con las decisiones relativas a la custodia y visita de menores, podrán ser modificadas por los tribunales españoles previo su reconocimiento a título principal o incidental. No obstante, también prevé que se pueda plantear una nueva demanda en un proceso declarativo ante los tribunales españoles. Será a la parte interesada a la que corresponde la elección por una u otra opción, en los términos del artículo $45^{21}$. Dado que en el supuesto que nos ocupa no se ha planteado un nuevo procedimiento de atribución de medidas es necesario, conforme al precepto citado, reconocer la decisión extranjera cuya modificación se pretende.

\section{Precisión del sistema de reconocimiento aplicable}

30. El procedimiento a seguir para el reconocimiento propuesto dependerá de la norma aplicable para otorgar eficacia en España a la sentencia dictada por el tribunal marroquí. En este punto, conforme al artículo 52.2 del Convenio de La Haya de 1996, este no afectará a los acuerdos que puedan concluir los Estados Parte sobre las materias en él reguladas respecto de menores que tengan su residencia en uno de los Estados Parte de dichos acuerdos. Procederá, entonces, la aplicación de algunos de los dos Convenios celebrados entre España y Marruecos el 30 de mayo de 1997 debiendo dar preferencia, por su especialidad y de acuerdo con las normas sobre Derecho de los Tratados, al texto relativo a la asistencia judicial y reconocimiento y ejecución de decisiones relativas a derecho de custodia, derecho de visita y devolución de menores, antes citado. Solución que no acoge la Sala cuando determina la aplicación del régimen de reconocimiento y ejecución de resoluciones judiciales previsto en los artículos 22 a 32 del Convenio de cooperación judicial en materia civil, mercantil y administrativa celebrado entre ambos Estados. No obstante, como tendremos ocasión de exponer, la aplicación de este último texto podría encontrar su fundamento en el principio de favor recognitionis si el sistema de reconocimiento en el previsto es más favorable.

31. El Convenio bilateral sobre asistencia judicial y reconocimiento y ejecución de decisiones relativas a derecho de custodia y visita, tiene por objeto, conforme a lo dispuesto en su artículo 1, "hacer que se reconozcan y ejecuten las resoluciones judiciales relativa a la custodia y al derecho de visita, dictadas en uno de los dos Estados contratantes en el territorio del otro Estado". A ello responde su capítulo III, que comprende los artículos 11 y 12 en los que, de un lado establece los motivos por los que es posible denegar el reconocimiento y, de otro, admite el reconocimiento parcial, al indicar en su artículo 12 que en aquellas resoluciones que contengan varios pronunciamientos, solo se aplicará el sistema en él previsto a los relativos a los derechos de custodia y visita. Esta regulación se completa con algunas disposiciones contenidas en su capítulo V en el que bajo la rúbrica "Disposiciones comunes" prevé que cada Estado aplique un procedimiento sencillo y rápido para el reconocimiento y ejecución de una resolución relativa al derecho de custodia o visita (artículo 14). Procedimiento que se regirá por la legislación del Estado requerido y sobre el que deberán informar los Estados Parte en los términos del párrafo segundo del artículo 14. Asimismo, en su artículo 16 relaciona los documentos que se deben acompañar a la solicitud, y en el artículo 18 hace referencia a la lengua en la que deben ir redactados y la necesidad de traducción en su caso ${ }^{22}$.

${ }^{21}$ A. Rodríguez Benot, "La ley de cooperación jurídica internacional en materia civil", Cuadernos de Derecho Transnacional, vol. 8 (2016), pp. 234-259; J.J. ALVAREZ RUBIO, “Artículo 45: Resoluciones extranjeras susceptibles de modificación”, en F.P. MÉNDEZ GONZÁLEZ/G. PALAO MORENO (Dirs) Comentarios a la Ley de cooperación jurídica internacional en materia civil, 2016, pp. 493-502.

${ }^{22}$ Véase M. SABido Rodríguez, "Consideraciones sobre el Convenio bilateral entre España y Marruecos de 1997”, en A.L.Calvo Caravaca/J.L. Iriarte Ángel (Dirs.) Mundialización y Familia, 2001, pp. 347-356. 
32. La referencia en el convenio al procedimiento previsto en la legislación del Estado requerido en el marco del citado convenio, supone la aplicación del sistema de eficacia extraterritorial de decisiones previsto en la LCJIMC. A partir de las previsiones contenidas en el artículo 45 LCJIMC, las posiciones que rechazaban la necesidad de reconocimiento carecen hoy de virtualidad. El precepto exige el reconocimiento, incidental o principal, de la decisión extranjera. En función de los efectos que se pretenda otorgar a la decisión extranjera procederá bien mediante el reconocimiento a título principal, que implica un procedimiento jurisdiccional a través del cual se declara el reconocimiento o, en su caso, el no reconocimiento de la decisión extranjera, bien mediante el reconocimiento incidental, lo que supone que, en el marco de un procedimiento que se sustancia ante los tribunales españoles, se deberá hacer valer la decisión extranjera para que pueda desplegar los efectos derivados del reconocimiento ${ }^{23}$. En este punto, como acertadamente afirma la Audiencia Provincial de Zaragoza a tenor de la dicción literal del Preámbulo de la LCJIMC, "respecto al reconocimiento de una resolución extranjera de forma incidental se ha evitado una referencia en el artículo 44.2 a la apertura de un incidente conforme a lo establecido en los artículos 388 y siguientes LEC, permitiéndose así que el reconocimiento incidental se pueda llevar a cabo de forma ágil y más sencilla en el seno de cada procedimiento según las leyes procesales, ya que el proceso incidental referido parece diseñado para otro tipo de cuestiones y su utilización supondría encajar un execuátur dentro de un proceso abierto cuando la solución puede ser más sencilla al plantearse normalmente el reconocimiento como base de la estimación o desestimación de la pretensión principal, de tal modo que será la sentencia la que determine la aptitud del documento para probar lo que se pretende", y que "Si se tratase de resolver con carácter previo una excepción procesal, en tal momento puede apreciarse también la aptitud del documento para probar las pretensiones" 24 .

33. El convenio bilateral sobre cooperación judicial, invocado por la Sala, en cambio, favorece el reconocimiento de la decisión marroquí al consagrar en su artículo 2 el reconocimiento de pleno derecho, también denominado reconocimiento automático. Un sistema de reconocimiento que, como ha puesto de relieve la doctrina, no está previsto en la LCJIMC a pesar de su inclusión en los textos europeos y de los beneficios que reporta al permitir el reconocimiento de la decisión extranjera sin tener que acudir a un pronunciamiento jurisdicciona ${ }^{25}$. Su aplicación supondría que, en el marco del procedimiento de modificación de las medidas adoptadas por la decisión marroquí, esta última goza del efecto de cosa juzgada de tal modo que el tribunal de instancia ante el que el procedimiento se ha planteado deberá verificar, de oficio ex artículo 26, que concurren las condiciones previstas en el artículo 23 del texto convencional, examen del que dejará constancia en su resolución. Para ello, la parte que invoca la decisión extranjera, el actor, deberá aportar los documentos relacionados en el artículo 28 del mismo texto legal y que se refieren a: una copia de la resolución que reúna las condiciones para su autenticidad; el original del documento de notificación de la resolución; certificado en el que conste que la resolución no ha sido objeto de recurso y una copia certificada de la citación, en su caso, a la parte condenada en rebeldía.

34. En su examen, el tribunal deberá constatar que concurren las condiciones a las que se refiere el artículo 23 del convenio son las generalmente previstas en los sistemas de eficacia extraterritorial de decisiones, esto es, que la decisión emana de un órganos jurisdiccional competente; que las partes han sido legalmente emplazadas en tiempo y forma; que la resolución goza en origen del efecto de cosa juzgada y, en su caso, ejecutivo; que la resolución no es contraria al orden público del Estado requerido ni a ninguna resolución dictada en dicho Estado y que no existiese ningún procedimiento pendiente en el Estado requerido antes de iniciarse la acción en el Estado de origen de la decisión.

\footnotetext{
${ }^{23}$ F. Garau Sobrino, “Artículo 42. Procedimiento de exequátur”, en F.P. Méndez González/G. Palao Moreno (Dirs.) Comentarios a la Ley de cooperación jurídica internacional en materia civil", 2016, p. 474-491.

${ }^{24}$ Véase el Auto de la Audiencia Provincial de Zaragoza de fecha 28 de noviembre de 2017 (ROJ: AAP Z 3178:2017 ECLI: ES:APZ:2017:3178A)

${ }^{25}$ F. Garau Sobrino, “Artículo 44. Reconocimiento”, en F.P. MÉNDEZ GONZÁLEZ/G. PALAO MORENO (Dirs) Comentarios a la Ley de cooperación jurídica internacional en materia civil, 2016, pp. 501-516.
} 